\title{
Revalorisation of the Szewalski's concept of the law of varying the last-stage blade retraction in a gas-steam turbine
}

\author{
Paweł Ziółkowski ${ }^{1 *}$, Stanisław Głuch ${ }^{1}$, Tomasz Kowalczyk ${ }^{2}$, and Janusz Badur ${ }^{2}$ \\ ${ }^{1}$ Gdańsk University of Technology, Faculty of Mechanical Engineering and Ship Technology, Institute of Energy, Narutowicza \\ 11/12, 80-233 Gdańsk \\ ${ }^{2}$ Institute of Fluid-Flow Machinery Polish Academy of Sciences, Energy Conversion Department, Fiszera 14, 80-231 Gdańsk, \\ Poland
}

\begin{abstract}
The article presents the implementations of the free vortex law to the blade of the last stage of a gas- steam turbine. First, a thermodynamic analysis was carried out, determining the parameters at the inlet, then the number of stages of the high and low-pressure part of the turbine was constructed, together with the kinematics and velocity vectors for subsequent stages of the axial turbine. The last step of article was to take into account the law of variation of the peripheral component of the velocity of the medium working with the radius of the turbine in a discrete way and to make a 3D drawing of the resulting geometry. When creating the spatial model, the atlas of profiles of reaction turbine stages was used.
\end{abstract}

\section{Introduction}

Although the issue of shaping the turbine blades has appeared in literature since the beginning of the last century [1], there are new concepts appeared over the years [2,3]. There was a big development not only in the concepts themselves, but also in a research tool, which, starting with analytical tools [1] and was transformed over the years into analyzes taking into account sophisticated numerical tools [4-7]. Currently, turbine companies rely on a fully three-dimensional approach, both in the case of stress analyzes related to the solid as well as analyzes increasing the efficiency - flow analyzes [8]. This paper is purely theoretical analyses of turbine with a steam-gas working fluid produced in a wet combustion chamber. The concept of this cycle was developed in the dissertation of P. Ziółkowski [9].

The paper presents the results of thermodynamic analysis, which gives the basis for a full flow analysis in the stages of the reaction turbine. The aim of the work was to adapt the law of curling based on a free vortex to a gas-steam turbine. In the last point, Szewalski's concept of the law of differential folding was mentioned.

\section{Thermodynamic parameters and kinematics of the gas-steam turbine}

Fig. 1 shows a diagram of a compact gas-steam power plant, where the key element is the original "wet combustion chamber", which is a steam-gas generator.

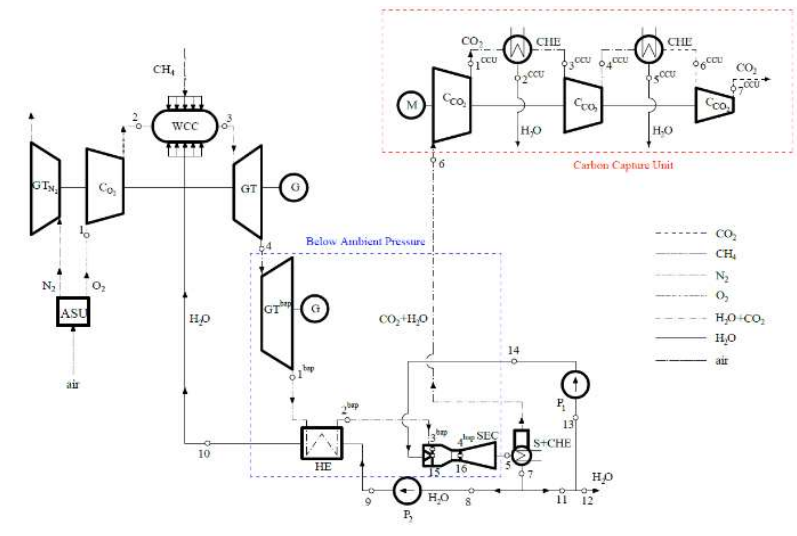

Fig. 1. The cycle of a compact, high-efficiency and emissionfree power plant [9]: SEC - spray-ejector condenser, WCC wet combustion chamber, GT $+\mathrm{GT}^{\text {bap }}$ - gas turbine divided into two parts $\left(\mathrm{GT}+\mathrm{GT}^{\text {in }}\right.$ - gas-steam turbine - second name: GT high-pressure and $\mathrm{GT}^{\text {in }}$ low-pressure,), ASU - air separation unit, C - compressor, HE - heat exchanger, CHE + $\mathrm{S}$ - condensate-cooler heat exchanger and separator, CHE - cooling heat exchanger, $\mathrm{M}$ - motor, $\mathrm{G}$ - generator, $\mathrm{P}_{1}$ supply water pump, $\mathrm{P}_{2}$-water pump for cooling combustion chamber, $\mathrm{GT}_{\mathrm{N} 2}-$ expander $\mathrm{N}_{2}, \mathrm{C}_{\mathrm{CO} 2}-\mathrm{CO}_{2}$ compressor.

In the mentioned wet combustion chamber (WCC), the product of the oxygen combustion of gases, combined with the "nanoproduction" of steam, is a working medium containing about $80-90 \%$ of steam and $20-10 \%$ of $\mathrm{CO}_{2}$, so it is important to properly separate the water vapor from the $\mathrm{CO}_{2}$. The original ideas proposed in [9] are also: 1) the introduction of the ejector as a spray-jet condenser for water condensation that separates $\mathrm{CO}_{2}$, and 2) the use of a gas-steam turbine. Fig. 2 shows the shape of the expander, that ensure optimal use of the enthalpy of the working medium in GT $+\mathrm{GT}^{\text {in. }}$ The turbine casing was divided into high-pressure part (Fig. $2 a$ ), and low-pressure part (Fig $2 b$ ), where geometry of

*Corresponding author: e-mail: pawziolk@pg.edu.pl; 
flow channels is presented. Dual-outlet low-pressure part was introduced.

a)

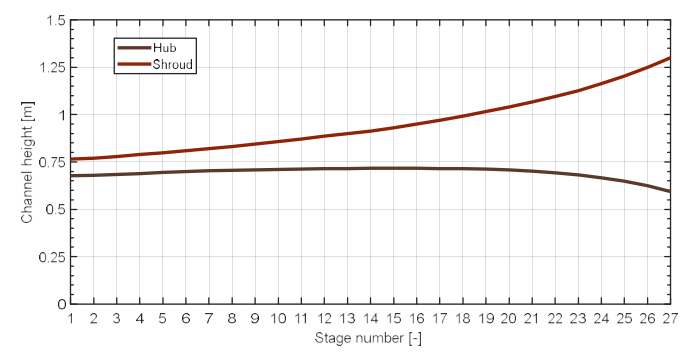

b)

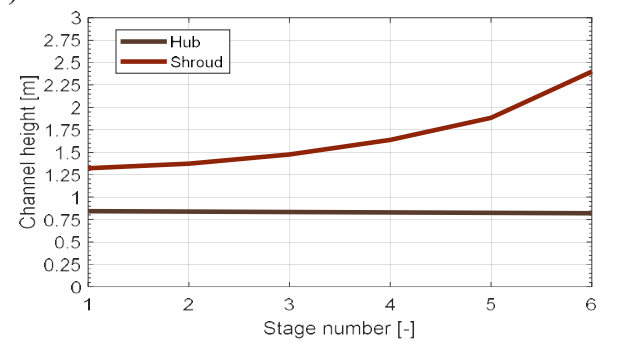

Fig. 2. Flow channel of the high-pressure (GT) and lowpressure $\left(\mathrm{GT}^{\mathrm{in}}\right)$ end of a gas- steam turbine dual-outlet, where orange line is the top (shroud) and black one is feet of the stator blades (hub) - the opposite is true for the rotor.

A special attention should be paid to the fact that the part of high pressure fluid flows with the mass flow rate of $182.3 \mathrm{~kg} / \mathrm{s}$, and the low pressure part flows with velocity of the $91.15 \mathrm{~kg} / \mathrm{s}$, with each channel of dualoutlet gas-steam turbine. Calculations of the shape of the turbine were made on the basis of the methodology of designing multi-stage axial turbines [8], but taking into account steam-gas as a working medium. Based on thermodynamic parameters such as inlet pressure $\mathrm{p}_{0}=$ 40 bar, temperature $\mathrm{t}_{0}=1338^{\circ} \mathrm{C}$, and gas composition, the specific enthalpy at the turbine inlet was determined at $\mathrm{h}_{0}=4959 \mathrm{~kJ} / \mathrm{kg}$. Next, the assumptions typical for a multi-stage axial turbine were established and calculations were carried out. Design assumptions for the high-pressure part (GT) and some of the results are presented in Table 1.

Table 1. Examples of assumptions concerning the highpressure part of turbine (GT).

\begin{tabular}{|l|l|l|l|l|}
\hline & & 1 & 15 & 27 \\
\hline$\rho$ & - & 0.5 & 0.5 & 0.5 \\
\hline$H_{S}$ & $\mathrm{~kJ} / \mathrm{kg}$ & 60 & 67 & 73 \\
\hline$h_{0}$ & $\mathrm{~kJ} / \mathrm{kg}$ & 4959 & 4113 & 3316 \\
\hline$p_{0}$ & $\mathrm{bar}$ & 40 & 9.21 & 1.45 \\
\hline$s_{0}$ & $\mathrm{~kJ} /(\mathrm{kg} \cdot \mathrm{K})$ & 8.113 & 8.140 & 8.176 \\
\hline$\alpha_{1}$ & & & & \\
& $\mathrm{o}$ & 20.5 & 22 & 25 \\
\hline$\vartheta$ & - & 0.654 & 0.706 & 0.778 \\
\hline$\mu_{1}$ & - & 0.96 & 0.96 & 0.96 \\
\hline$\varphi$ & - & 0.98 & 0.98 & 0.98 \\
\hline$\psi$ & - & 0.98 & 0.98 & 0.98 \\
\hline$c_{0}$ & $\mathrm{~m} / \mathrm{s}$ & 0 & 107.6 & 137.4 \\
\hline$n$ & $\mathrm{rot} / \mathrm{min}$ & 3000 & 3000 & 3000 \\
\hline$\dot{m}$ & $\mathrm{~kg} / \mathrm{s}$ & 182.3 & 182.3 & 182.3 \\
\hline
\end{tabular}

Detailed calculations of the axial degree kinematics were performed for both the GT and GT ${ }^{\text {in }}$ parts. Thus, a similar table can be prepared for the low-pressure part $\left(\mathrm{GT}^{\mathrm{in}}\right)$, where an exemplary result in the form of velocity triangles is shown in Fig. 3.

A large differences in the specific volume of the medium between the high-pressure part and the low-pressure part caused large change in the shape of velocity triangles in the low-pressure part as compared to those available in the literature [10]. In order to obtain a smooth shape of the channel, significant changes in parameters such as reactivity, velocity index, enthalpy drop and angle $\alpha_{1}$ have to be made. It is worth to pay special attention to the last velocity triangle, the shape of which differs significantly from the typical velocity triangle. This is due to the high reactivity, which makes the velocity $c_{2 a}$ greater than $c_{1} a$ and the high value of the velocity index $\vartheta=u / c_{s}$. The reactivity in the part of $\mathrm{GT}^{\text {in }}$ reaches the value of $\rho=0.7$, and the velocity index to $\vartheta=0.88$, which is higher than those in Table 1, where typical indicators are given, respectively: $\rho=0,5$ and $\vartheta=0.654$ -0.778 .

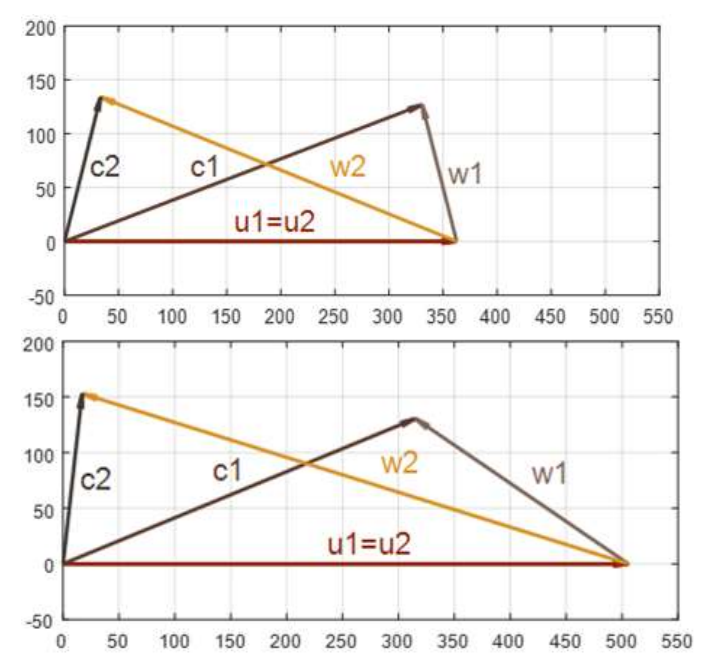

Fig. 3. Velocity triangles of low pressure part for stage: a) LP 4 and b) LP6, where: $u$ is the peripheral velocity, $w$ is the relative velocity, and $\mathrm{c}$ is the absolute velocity.

According to Fig. 2 the number of axial stages, respectively: 27 degrees for the high-pressure part (GT) and 6 degrees for the low-pressure part $\left(\mathrm{GT}^{\mathrm{in}}\right)$ which contain with the thermodynamic parameter the main result. The length of the last stage rotor blade reached value $l_{w}=1.57 \mathrm{~m}$, which is comparable to the blades operating in the newest steam unit at Kozienice Power Plant. In addition, it should be mentioned that the present turbine is a dual-case turbine: the high-pressure (GT) and low-pressure (GT ${ }^{\text {in }}$ ) part, and that the lowpressure part is dual-outlet.

\section{Model of a vane coiling on the height of the radius}

After the velocity triangle was obtained in the last stage of the low-pressure turbine (Fig. 3. LP6), the blade winding procedure was started. For this purpose, the height of the entire blade was divided into 15 sections. 
There are significant changes in the kinematics degree, as we depart from the assumption that the channel is homogeneous along the height of the radius. In order to increase the efficiency of the turbine, the shape of the blades should be adapted to the changing flow by changing the angles $\alpha$ and $\beta$ so as to adjust the shape of the blades to the changing peripheral velocity $u$. Coiling was performed using the slow whirl method presented in the book by Professor Perycz [11], because this method is described the most accurately. In the further part of the work we will also refer to the proposal of prof. Szewalski [1,2].

Usually, the law of curling of the second vane, and thus the law of variation in the peripheral velocity of the medium working with the radius, is different for the inlet to the vane channel and the outlet. In engineering practice, it is assumed that the velocity component $c_{2 u}$ at the inlet supposed to be as small as possible and should not be increased unnecessarily due to the decrease in efficiency by dissipating the kinetic energy of the factor operating at the outlet [8]. Thus, the vane winding procedure was based on the slow vortex method. The most important calculation steps will be introduced. beginning with the division of the height of the shoulder blades discreetly into 15 sections:

$$
\Delta l_{k}=\frac{l_{k}}{n} ; \Delta l_{w}=\frac{l_{w}}{n}
$$

It is equally important to determine the inflow angle $\alpha_{1}$ on successive sections by using the relationship The acknowledgements should be typed in 9-point Times, without title.

$$
\tan \alpha_{1 u s t}=\frac{\alpha_{1 m} \cdot \pi / 180}{r_{u s t} / r_{m}} ; \tan \alpha_{1}=\frac{r_{2}}{r_{u s t}} \cdot \tan \alpha_{1 u s t}
$$

Where $: r_{m}-$ medium radius, $\alpha_{1 m}$ average angle inflow, $\alpha_{1 u s t}{ }^{-}$inflow angle of the foot, $r_{2}$ - the radius of the rotor for a given section, $r_{u s t}-$ he radius of the rotor rate. The degree reactivity is determined by the formula:

$$
\rho=1-\left(1-\rho_{u s t}\right) \cdot\left(\frac{r_{u s t}}{r_{1}}\right)^{k}
$$

where : $\rho_{\text {ust }}=0.1$ is assumed as initial,,$r_{1}$ - steering wheel radius on a given discretization segment, $k=$ $2 \cos \alpha_{1}$ coefficient for reactivity correction. Based on the continuity equation, we determine the mass flux at individual sections:

$$
\Delta \dot{m}=\frac{\mu_{1} \cdot c_{1 s} \cdot \Delta A_{1} \cdot \sin \alpha_{1}}{v_{1 s}}
$$

where: $\Delta A_{1}=2 \cdot \pi \cdot r_{2}$ is the area of a s is the absolute velocity, $v_{1 s} \mathrm{~s}$ is the relative velocity. The calculation procedure also determines the angle $\beta$ and velocity components for individual velocity triangles, blade losses for successive sections, power and efficiency.

The calculations are carried out in an iterative way and the parameter to be compared is the mass flux, because the value of the sum $\Delta \dot{m}$ from individual discretization segments should agree with $\dot{m}=91.15$ $\mathrm{kg} / \mathrm{s}$.

The initial assumptions for the twisted degree are summarized in Table 2. In turn, the assumed degree parameters needed to perform the winding calculations for selected discretization sections are presented in Table 3.

Table 2. Initial assumptions about the twisted step.

\begin{tabular}{|c|c|c|}
\hline$\rho_{n}$ & - & 0.1 \\
\hline$r_{n 1}$ & $\mathrm{~m}$ & 0.820115209 \\
\hline$r_{n 2}$ & $\mathrm{~m}$ & 0.820115209 \\
\hline$H_{s c}$ & $\mathrm{~kJ} / \mathrm{kg}$ & 178.6120643 \\
\hline$H_{s}$ & $\mathrm{~kJ} / \mathrm{kg}$ & 165 \\
\hline$l_{k}$ & $\mathrm{~m}$ & 1.293335645 \\
\hline$l_{w}$ & $\mathrm{~m}$ & 1.578019487 \\
\hline$\omega$ & $\mathrm{rad} / \mathrm{s}$ & 314.1592654 \\
\hline$\alpha_{1}$ & $\mathrm{o}$ & 22.5 \\
\hline$p_{0}$ & $\mathrm{MPa}$ & 0.016255325 \\
\hline$h_{0}$ & $\mathrm{~kJ} / \mathrm{kg}$ & 2695.346123 \\
\hline$s_{0}$ & $\mathrm{~kJ} /(\mathrm{kg} \cdot \mathrm{K})$ & 8.254181075 \\
\hline$\dot{m}$ & $\mathrm{~kg} / \mathrm{s}$ & 91.15 \\
\hline$c_{0}$ & $\mathrm{~m} / \mathrm{s}$ & 164.9973594 \\
\hline$n$ & - & 15 \\
\hline$\Delta l_{k}$ & $\mathrm{~m}$ & 0.086222376 \\
\hline$\Delta l_{w}$ & $\mathrm{~m}$ & 0.105201299 \\
\hline$\alpha_{1 n}$ & $\circ$ & 11.92069374 \\
\hline
\end{tabular}

Table 3. Assumptions concerning selected sections of a twisted shoulder blade.

\begin{tabular}{|c|l|r|r|r|r|r|}
\hline parameter & unit & 1 & 4 & 8 & 12 & 15 \\
\hline$\mu_{1}$ & - & 0.94 & 0.94 & 0.94 & 0.94 & 0.94 \\
\hline$\mu_{2}$ & - & 0.94 & 0.94 & 0.94 & 0.94 & 0.94 \\
\hline$\varphi$ & - & 0.935 & 0.95 & 0.95 & 0.95 & 0.95 \\
\hline$\psi$ & - & 0.925 & 0.935 & 0.935 & 0.935 & 0.935 \\
\hline
\end{tabular}

Table 4 presents the calculation results for five partition sections. Segment number 8 is on the pitch diameter. Due to very large changes in the value of the peripheral velocity, $u$, there are large changes in the reactivity, angles and velocity along the radius. The value of the peripheral speed, $u$, varies from, , $u=262$ $\mathrm{m} / \mathrm{s}$ to $u=771 \mathrm{~m} / \mathrm{s}$. The speed of sound in this region of the steam is around $440 \mathrm{~m} / \mathrm{s}$.

It should be noted that at the foot the scapula is action-packed and at the tip it is extremely reactive. A minimum reactivity of 0.1 is found at the foot. This value should not drop below $\rho=0,1$, to avoid a negative reaction value during operation with partial power. The reactivity at the apex is as high as $\rho=0,89$. Figure 4 shows the velocity triangles for selected partition sections. 


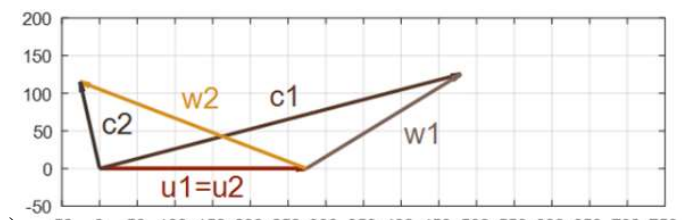

a)

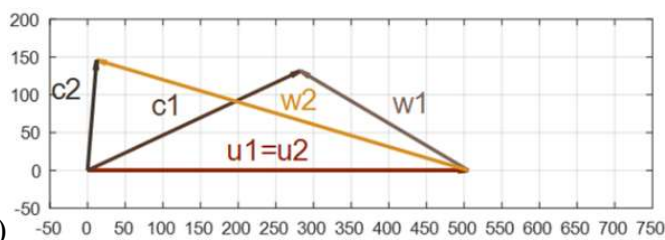

b) ${ }^{-50} \quad 0 \quad 50 \quad 100150200250300 \quad 350400450500550600650700750$

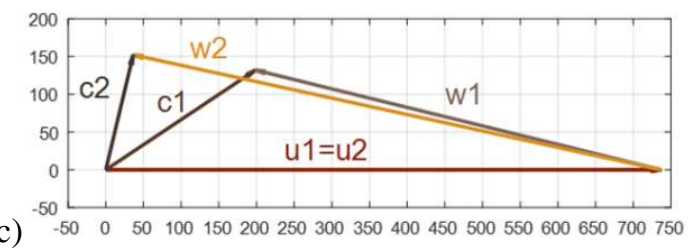

Fig.4. Velocity triangles of the stator and rotor blade with the distinction of a) the base (foot) of the rotor blade; b) mean diameter; c) the tip of a rotor blade, where: $u$ is the peripheral speed, $w$ is the relative speed, and c is the absolute speed.

It is noteworthy that a large velocity changes along the pitch diameter. At the foot there are three stocks Fig. 4a). In turn, the pitch diameter is already reactionary (4b)). On the other hand, at the top one can observe the most different velocity triangle 4c) compared to what occurs at the base. Fig. 5 shows the 3D geometry of the steer blade and the impeller designed based on the law of free vortex.

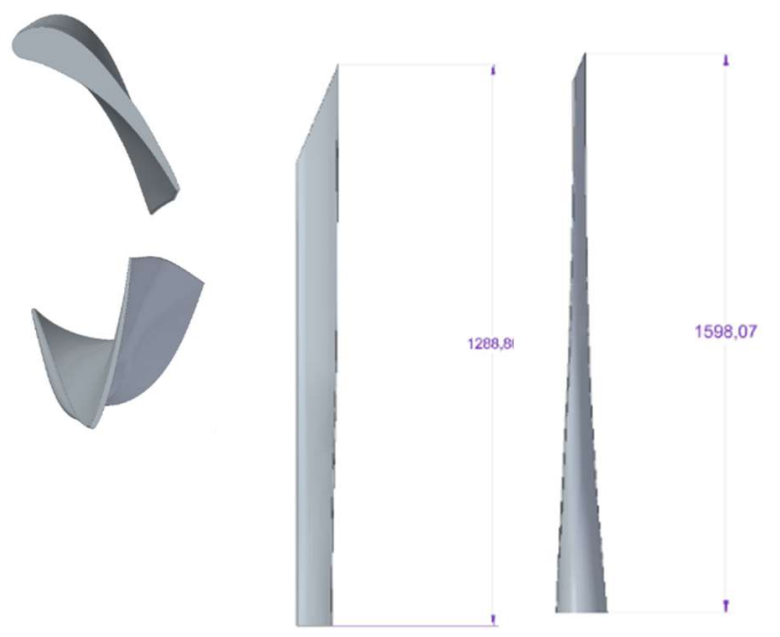

Fig. 5. Top and front view - steering blade and rotor blade, where the blade length is $1289 \mathrm{~mm}$ and the rotor blade length is $1598 \mathrm{~m}$.

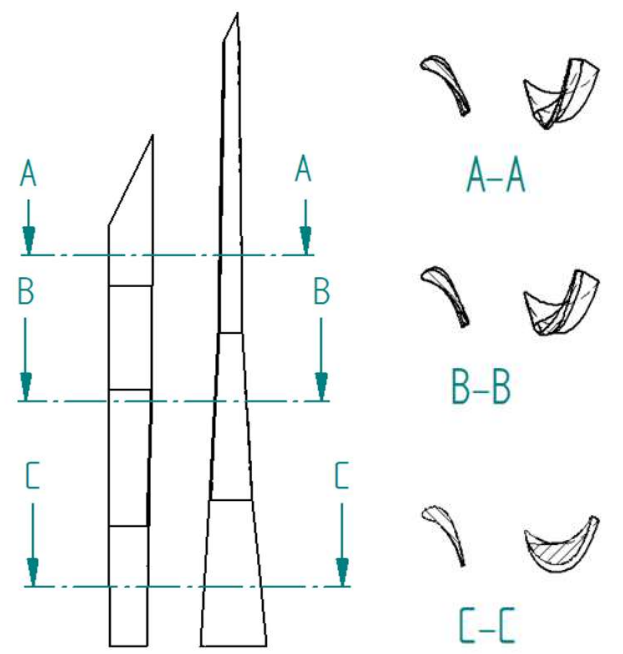

Fig. 6. View at selected sections of the steering and rotor vanes.

In turn, Fig. 6 presents the most important cross-sections in selected places of the steering and rotor blades. It can be also seen that a characteristic stock-type profile appears at the base, and that towards the top of the blade it begins to take an increasingly reactive shape.

\section{Conclusion}

In the case of revalorization of Szewalski's concept, the law of free vortex winding should be extended to include a new method of determining the blade profile. Unfortunately, this is a specific challenge that has been met with the Martaniemi blade in Lappeenranta, Finland. To solve this problem, it is worth changing the conventional type of working blades, characterized by a constant profile and constant inlet and outlet angles, to blades coiled along the height of the radius, but taking into account the two laws of curl. Thus, the lobes of the present vanes are constructed of different profiles and the inlet and outlet angles vary according to the nature of the flow. Another way to improve the efficiency of the stage is to use optimization methods, which ensure that in the case of the last stage with spatially twisted blades, the efficiency is increased by about 4 percentage points [12].

In this study, a new stage was designed using the free vortex winding law for a new proposal for a gas-steam turbine, where the working medium is steam-gas. The implementations of the free vortex to the blade of the last stage of a gas and steam turbine. First, a thermodynamic analysis was carried out, determining the parameters at the inlet, then the number of stages of the high and low-pressure part of the turbine was determined, together with the kinematics and velocity vectors for subsequent stages of the axial turbine. The last step was to take into account the law of variation of the peripheral component of the velocity of the medium working with the radius of the turbine in a discrete way and to make a 3D drawing of the resulting geometry. When creating the spatial model, the atlas of profiles of reaction turbine steps was used. To further improve the efficiency more effort similar to presented in [13-15] 
should introduce to analyse flow characteristics and stress level for new type of cycle which can be developed in negative $\mathrm{CO}_{2}$ power plant.

The research leading to these results has received funding from the Norway Grants 2014-2021 via the National Centre for Research and Development. Article has been prepared within the frame of the project: "Negative $\mathrm{CO} 2$ emission gas power plant" - NOR/POLNORCCS/NEGATIVE-CO2$\mathrm{PP} / 0009 / 2019-00$ which is co-financed by programme "Applied research" under the Norwegian Financial Mechanisms 2014-2021 POLNOR 2019 - Development of $\mathrm{CO} 2$ capture solutions integrated in power and industry processes.

\section{References}

1. R. Szewalski, Czasopismo Techniczne. XLVIII, no 1, 83-86 (1930)

2. R. Szewalski, Trans IFFM, 70-72, 137-143 (1976)

3. Ł. Witanowski, P. Klonowicz, P. Lampart, T. Suchocki, Ł. Jędrzejewski, D. Zaniewski, P. Klimaszewski, Energy 205, 118059 (2020)

4. J. Badur, P. Ziółkowski, S. Kornet, T. Kowalczyk, K. Banaś, M. Bryk, P.J. Ziółkowski, M. Stajnke, J. of Theoretical and Appl. Mechanics 56-1, 329-332 (2018)

5. P. Ziółkowski, J. Badur, Int. J. of Numerical Methods for Heat \& Fluid flow 28-1, 64-80 (2018)

6. T. Ochrymiuk, J. of Thermal Science 26-5,459464 (2017)

7. B. Kraszewski, Case Studies in Thermal Engineering 21, 100728 (2020)

8. D. Zaniewski, P. Klimaszewski, P. Klonowicz, P. Lampart, Ł. Witanowski, , Ł. Jędrzejewski, T. Suchocki , Ł. Antczak, Energy 226, 120242 (2021)

9. P. Ziółkowski, Analiza termodynamiczna niskoemisyjnych obiegów gazowo-parowych z zastosowaniem oksyspalania. $\mathrm{PhD}$ thesis 2018, IMP PAN Gdańsk

10. Ł Kowalczyk, W. Elsner, P. Niegodajew, M. Marek, Applied Thermal Engineering 96, 200-208 (2016).

11. S. Perycz, Steam and gas turbine, Gdańsk University of Technology Publisher, Gdańsk, (1988)

12. P. Ziółkowski, Ł. Witanowski, P. Klonowicz, S. Głuch, Optimization of the last stage of gas-steam turbine using a hybrid method. Proceedings of 14th European Conference on Turbomachinery Fluid dynamics \& Thermodynamics. ETC14, April 12-16 2021; Gdansk, Poland. Paper ID: ECT2021-791.

13. D. Zaniewski, P. Klimaszewski, Ł. Witanowski, , Ł. Jędrzejewski , P. Klonowicz , P. Lampart, Archives of Thermodynamics 40, 137-157(2019)

14. M. Froissart, P. Ziółkowski, W. Dudda, J. Badur, Case Studies in Thermal Engineering 28, 101445 (2021)

15. J. Badur, P. Ziółkowski, D. Sławiński, S. Kornet, Energy 92,142-152 (2015) 